Raquel Fraga Silva

RAIMONDO ${ }^{1}$

João Paulo Elsen SAUT ${ }^{1}$

Regiane Machado SOUZA ${ }^{1}$

Mariana Tikuma NUNES ${ }^{1}$

Eduardo Harry BIRGEL

JUNIOR ${ }^{1}$

\section{Correspondência para:}

Eduardo Harry Birgel Junior, Departamento deClínica Médica-FMVZ - USP, Av. Prof. Orlando Marques de Paiva 87 Cidade Universitária Armando Salles de Oliveira 05508-900 São Paulo - SP, ehbirgel@usp.br

Recebido para publicação: 25/08/2006 Aprovado para publicação: 27/08/2009

\title{
Teores de proteína, gordura e sólidos totais no leite de vacas da raça Jersey criadas no Estado de São Paulo durante o primeiro mês de lactação
}

\author{
1 - Centro de Pesquisa e Diagnóstico de Enfermidades de Ruminantes do \\ Departamento de Clínica Médica da Faculdade de Medicina Veterinária e \\ Zootecnia da Universidade de São Paulo, São Paulo-SP
}

\section{Resumo}

Com a finalidade de estabelecer os valores de referência dos teores de proteína, gordura e sólidos totais do leite de bovinos da raça Jersey, criados no Estado de São Paulo, durante o primeiro mês de lactação, bem como avaliar a influência da fase colostral, examinaram-se 418 amostras de leite, provenientes de quartos mamários sadios e sem crescimento bacteriano. O leite foi colhido assepticamente antes da ordenha e os valores de proteína, gordura e sólidos totais foram determinados por radiação infra vermelho. Os teores de proteína na secreção láctea diminuíram abruptamente do $1^{\circ}$ para o $2^{\circ}$ dia de lactação, enquanto os teores de sólidos totais diminuíram abruptamente nas primeiras 24 horas após o parto. Após oscilaram muito nos primeiros três dias de lactação, observou-se que os valores de gordura diminuíam atingindo os valores mínimos entre o $15^{\circ}$ e $30^{\circ}$ dia de lactação. Sugerese nas primeiras 24 horas de lactação (período colostral) a adoção dos seguintes valores de referência: proteína - entre 7,35 e 11,45 g/dL; gordura - 0,98 e 2,00 g/dL; e sólidos totais - entre 12,39 e 19,45 g/dL

\section{Introdução}

Dentre os fatores responsáveis pelas alterações na composição e nas propriedades físico-químicas do leite merecem destaque aqueles decorrentes das mamites que podem acometer bovinos em qualquer das fases da lactação. No diagnóstico das mamites, o clínico veterinário, deve realizar, além do exame físico da glândula mamária, testes e provas complementares que avaliam a resposta inflamatória e ou a extensão da lesão provocada.

Até recentemente as modificações da constituição protéica do leite eram consideradas de menor importância no diagnóstico da mamite. Entretanto os resultados obtidos por Sant ${ }^{\prime}$ Ana $^{1}$ evidenciaram, de forma inconteste, a importância da determinação do proteinograma lácteo, pois foi comprovado que nas mamites ocorria o aumento dos teores de proteína total com diminuição dos teores de caseína e que o aumento dos teores de proteínas de origem plasmática no soro lácteo representavam sintoma evidente de alteração da glândula mamária com passagem de plasma sangüíneo para o leite.

Em relação aos teores lácteos de gordura é fato conhecido que a gordura representaria um obstáculo físico para a condução de eletricidade ${ }^{2}$, sendo os valores de eletrocondutividade diretamente influenciados por sua variação nas amostras de leite. Assim a determinação dos teores de gordura poderia ser utilizada como um fator de correção para os resultados obtidos na mensuração dos valores de eletrocondutividade do leite, melhorando a interpretação clínica dos resultados, quando se usar o segundo teste mencionado para fins de diagnóstico. ${ }^{2}$

Pesquisas desenvolvidas no Departamento de Clínica Médica e no Centro de Pesquisa e Diagnóstico de Enfermidades de Ruminantes (CPDER) do 
Departamento de Clínica Médica da Faculdade de Medicina Veterinária da Universidade de São Paulo ${ }^{1,2,3,4}$ permitem afirmar que durante o período de lactação plena (entre 7 e 305 dias de lactação) os valores de proteína variam entre 3,28 e $3,77 \mathrm{~g} / \mathrm{dL}$, de gordura entre 1,74 e $2,98 \mathrm{~g} / \mathrm{dL}$ e de sólidos totais entre 10,84 e 11,82 g/dL.

Apesar da contribuição das pesquisas terem permitido a avaliação da influência de diversos fatores como a fase da lactação, ${ }^{1,2,3,4}$ do quarto mamário ${ }^{1,4}$, da retenção láctea ${ }^{5} \mathrm{da}$ presença da infecção bacteriana $a^{1,2,3,4}$ e da ocorrência da mamite ${ }^{2,4}$, ainda, não foram estabelecidos os padrões de referência brasileiros para os teores lácteos de proteína, gordura e sólidos totais da secreção láctea de vacas sadias durante a fase colostral.

As significativas modificações da constituição láctea observadas durante a fase colostral tornam necessário que sejam adotados valores padrões de referência, especialmente determinados para a primeira semana de lactação. Assim, a presente pesquisa teve a finalidade de avaliar os valores de proteína, gordura e sólidos totais no primeiro mês de lactação, procurando estabelecer os valores de referência para a fase colostral e avaliar as alterações ocorridas dos 30 primeiros dias da lactação.

\section{Material e Método}

Foram utilizadas 418 amostras de leite sem isolamento bacteriano no exame microbiológico proveniente de 127 vacas. As amostras de secreção láctea foram agrupadas em oito momentos de acordo com a fase de lactação em que se encontravam, conforme discriminado na tabela 1 .

O material utilizado foi colhido em propriedades situadas no Estado de São Paulo, sendo as vacas mantidas em sistema de criação semi-intensivo. Os animais eram mantidos em pastos formados por capim Bracbiaria decunbens, Brachiaria brizanth on Cynodon spp (Coast cross ou Tifton), recebendo forragem e concentrado de acordo com as necessidades de mantença e produção. Utilizava-se como volumoso silagem de milho, sendo esta dieta complementada pelo fornecimento de farelo de soja, farelo e/ou caroço de algodão, polpa cítrica e cevada. Nessas propriedades adotava-se o sistema de ordenha mecânica. Antes da ordenha realizava-se a higiene do úbere por meio da imersão dos tetos em solução antisséptica a base de cloro e secagem com toalha de papel ou pano com solução anti-séptica. Após a ordenha, os tetos eram novamente imersos em uma solução

Tabela 1 - Constituição dos grupos experimentais para estabelecer os valores de referência e avaliação da influência da fase colostral nos teores de gordura, proteína e sólidos totais na secreção láctea de vacas da raça Jersey criados no Estado de São Paulo

\begin{tabular}{cccc}
\hline $\begin{array}{c}\text { Grupo } \\
\text { Experimental }\end{array}$ & Fase da Lactação & $\begin{array}{c}\text { Número de } \\
\text { Quartos }\end{array}$ & $\begin{array}{c}\text { Número de } \\
\text { animais }\end{array}$ \\
\hline A & $0 \dashv 12$ horas & 27 & 11 \\
B & $12 \dashv 24$ horas & 41 & 11 \\
C & $1-2$ dias & 47 & 15 \\
D & $2 \dashv 3$ dias & 50 & 14 \\
E & $3-5$ dias & 86 & 25 \\
F & $5-7$ dias & 48 & 13 \\
G & $7-15$ dias & 62 & 21 \\
H & $15-30$ dias & 57 & 17 \\
\hline & Total de amostras & $\mathbf{4 1 8}$ & $\mathbf{1 2 7}$ \\
\hline
\end{tabular}


anti-séptica a base de iodo.

A seleção das glândulas mamárias foi baseada no exame clínico, não sendo utilizadas aquelas que apresentaram episódios recorrentes de mamite, alterações das características macroscópicas do leite, como presença de grumos, detectadas na prova do fundo escuro, ou que na palpação, realizada após a ordenha, apresentaram alterações de consistência que pudessem estar relacionadas à existência de processo inflamatório agudo ou crônico, conforme as recomendações de Birgel ${ }^{6}$.

Após a antissepsia do orifício do teto, utilizando-se algodão embebido em álcool $70 \%$, foram desprezados os primeiros jatos de leite, para então realizar a colheita de cerca de cinco $\mathrm{ml}$ de leite, em frascos estéreis, os quais foram utilizados para o exame microbiológico. Em seguida, para a determinação dos valores de proteína, gordura e sólidos totais foram colhidos 40 $\mathrm{mL}$ de leite em frascos de plástico contendo 2 pastilhas do conservante bromopol (2-bromo-2-nitro-propano-1,3-diol) que foram enviados para o Laboratório de Fisiologia da Lactação do Centro de Tecnologia para o Gerenciamento da Pecuária de Leite - Departamento de Produção Animal da ESALQ - USP Piracicaba.

As amostras de leite, antes do início das análises, foram mantidas em banho-maria a $38^{\circ} \mathrm{C}$, durante 15 minutos, e a seguir, homogeneizadas, manualmente, sendo as determinações dos valores de gordura, proteína e sólidos totais no leite realizadas por radiação infravermelha utilizando-se o equipamento BENTLEY 2000 da Empresa Bentley Instruments Inc.

As amostras para o exame microbiológico foram semeadas em meio de ágar-sangue de ovino desfibrinado e incubadas a $37^{\circ} \mathrm{C}$, sendo realizadas leituras com 24, 48 e 72 horas de incubação. Os exames bacterioscópicos foram realizados em lâminas coradas pelo Método de Gram, sendo que o isolamento dos microorganismos foi realizado de acordo com as técnicas descritas por Lennette ${ }^{7}$.
Os resultados foram apresentados em média, desvio padrão, mediana e intervalo de confiança. A análise estatística dos dados foi efetuada, primeiramente, pelo Teste de Levene para avaliar a homogeneidade de variâncias entre os grupos. Após a transformação logarítmica dos dados, verificou-se que a homocedasticidade nas variáveis transformadas não foram aceitas. Para as variáveis gordura e sólidos totais a razão entre maior e menor variância foi menor do que cinco; permitindo que os dados fossem submetidos à análise de variância seguido da comparação dos pares de médias pelo método de comparações múltiplas de Dunnett T3. Para a variável proteína a razão entre maior e menor variância foi maior do que cinco; sendo necessária a utilização de modelo de regressão linear (GLM), supondo distribuição gama dos dados.,

\section{Resultados e Discussão}

A análise dos resultados apresentados na figura 1 demonstrou que os teores lácteos de proteína diminuíram durante o primeiro mês de lactação, sendo que nos grupos compostos por amostras colhidas com até 12 horas após o parto $(10,95 \pm 1,24 \mathrm{~g} / \mathrm{dL})$ e entre 12 e 24 horas após parto $(8,09 \pm$ $2,35 \mathrm{~g} / \mathrm{dL}$ ) foram encontrados os maiores valores para essa variável. Estas observações estão de acordo com os referidos na literatura compulsada na qual demonstrouse ser os teores lácteos de proteína maiores no colostro. $1,2,3,10,11,12,13,14,15,16$

Segundo Sant'Ana ${ }^{1}$, na fase colostral, são encontrados os menores valores de caseína associados ao significante aumento das proteínas de origem plasmáticas como imunoglobulinas e $\alpha_{1}$-antitripsina, além das proteínas sintetizadas na glândula mamária, como a fração $\beta$-lactoglobulina. Deve ser ressaltado, ainda, que a determinação dos teores de proteína no colostro é de grande valia na avaliação da qualidade imunológica da secreção oferecida aos bezerros neonatos, assegurando a adequada transferência de imunidade passiva para esses neonatos. 


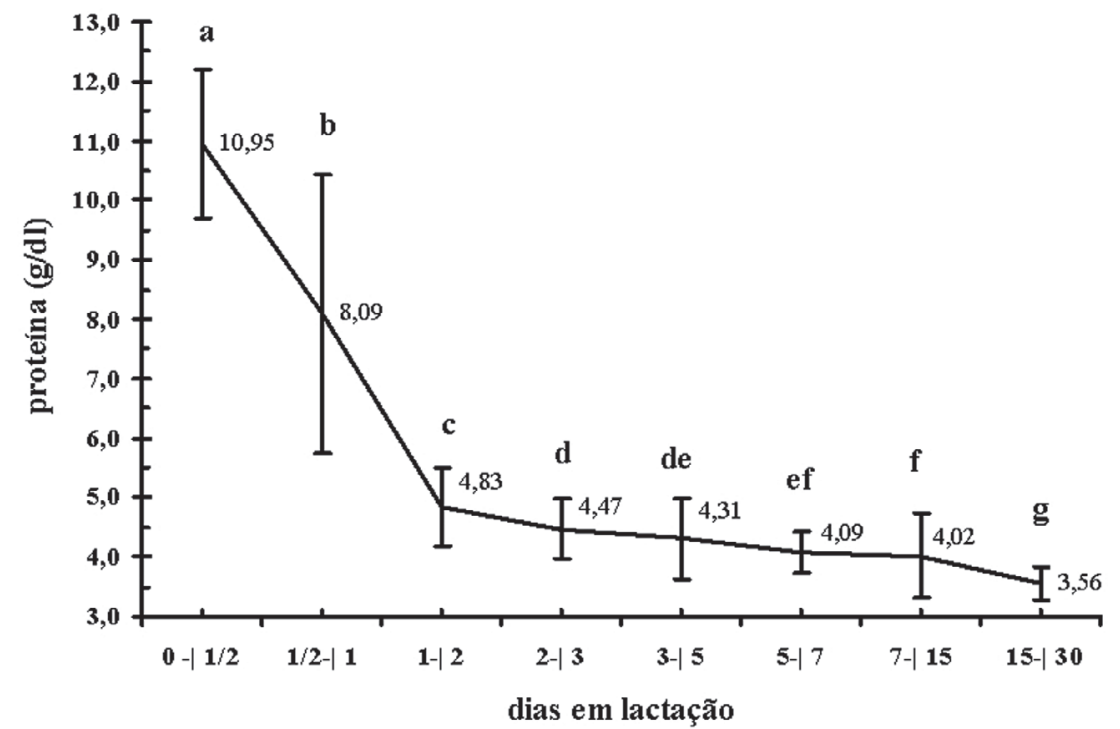

Figura 1 - Valores médios dos teores de proteína na secreção láctea de vacas da raça Jersey no primeiro mês de lactação (abcdefg - letras não coincidentes significam diferença estatística significante $(p \leq 0,05)$ Modelo de regressão linear)

Em amostras colhidas no $2^{\circ}$ dia de lactação $(4,83 \pm 0,66 \mathrm{~g} / \mathrm{dl})$ foram observados valores estatisticamente menores do que os encontrados nas primeiras 24 horas de lactação. Essa abrupta diminuição dos teores de proteína do $1^{\circ}$ para o $2^{\circ}$ dia de lactação já havia sido demonstrada anteriormente. ${ }^{2,15,16}$ Com o evoluir da lactação observou-se que entre o $2^{\circ}$ e $30^{\circ}$ dia de lactação os valores passam a diminuir gradualmente, atingindo, em amostras colhidas entre o $5^{\circ}$ e $7^{\circ}$ dia de lactação, teores lácteos iguais a 4,09 $\pm 0,35 \mathrm{~g} / \mathrm{dl}$ e, em amostras colhidas entre o $15^{\circ}$ e $30^{\circ}$ dia de lactação, iguais a 3,56 $\pm 0,29 \mathrm{~g} / \mathrm{dl}$.

Considerando os teores de proteína obtidos na presente pesquisa, verificou-se que a transição de colostro para leite ocorria a partir do $7^{\circ}$ dia de lactação. Uma análise sobre a literatura evidenciou que existe uma relativa concordância do momento em que ocorre esta transição, pois Estrella ${ }^{3}$ considerou como fase colostral amostras colhidas nos primeiro três dias de lactação, enquanto Birgel Junior ${ }^{2}$ observou que em amostras colhidas entre o $5^{\circ}$ e $7^{\circ}$ dia de lactação já apresentavam teores de proteína semelhantes aos verificados em vacas em plena lactação.
Conforme apresentado na figura 2, após oscilaram entre 1,35 \pm 1,17 g/dl e 3,09 $\pm 2,19 \mathrm{~g} / \mathrm{dl}$ nos primeiros três dias de lactação, verificou-se que os teores lácteos de gordura diminuíram atingindo os valores mínimos entre o $15^{\circ}$ e $30^{\circ}$ dia $(1,96 \pm$ $0,99 \mathrm{~g} / \mathrm{dL})$. Os resultados obtidos na presente pesquisa concordaram com Estrella ${ }^{3}$, Andrew ${ }^{10}$ e Parrish et al. ${ }^{16}$ que também verificaram uma oscilação dos teores de gordura nos primeiros dias de lactação.

$\mathrm{Na}$ literatura compulsada, encontraram-se citações referentes ao sistema de manejo alimentar, determinando significativa influência nos teores de gordura do leite. ${ }^{17}$ Segundo Brito et al. ${ }^{18}$, as variações dos teores lácteos de gordura seriam decorrentes, principalmente, das variações da quantidade de gordura sintetizada nos ácinos da glândula mamária a partir dos ácidos graxos de cadeia curta (acetato e butirato), produzidos durante a fermentação ruminal de forragens e outros alimentos ricos em fibras. Pelas características do manejo alimentar dos rebanhos de bovinos produtores de leite utilizados nesta pesquisa foi assegurado que na alimentação dos animais utilizados havia a quantidade de fibras necessárias para a produção da 


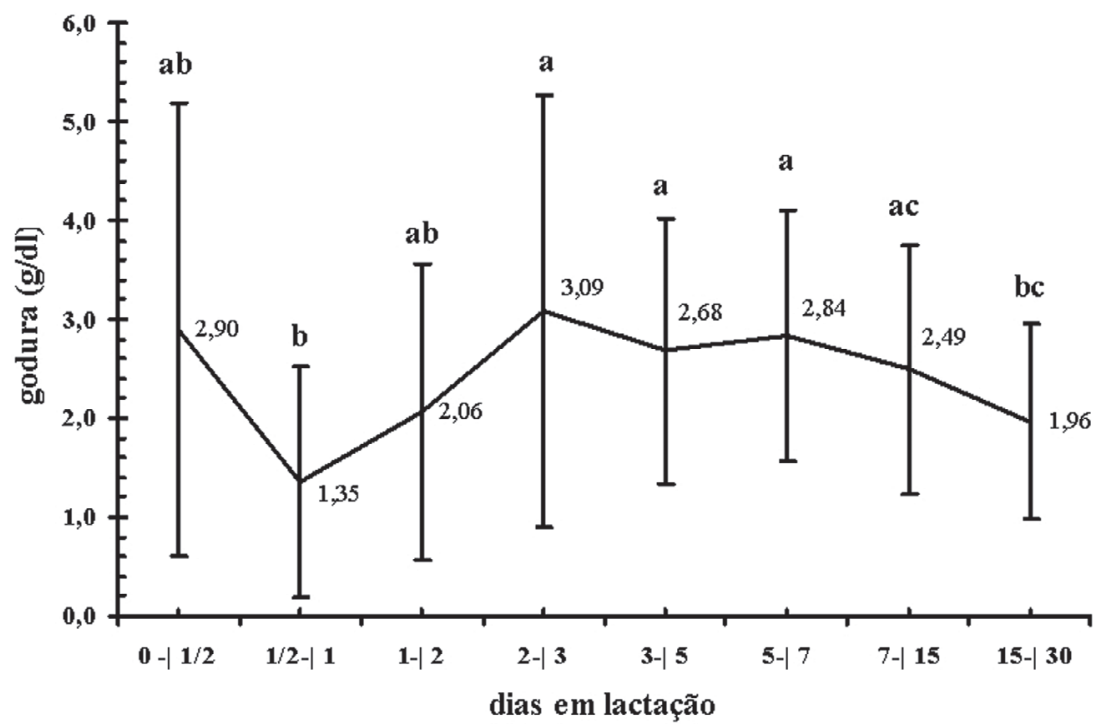

Figura 2 - Valores médios dos teores de gordura na secreção láctea de vacas da raça Jersey no primeiro mês de lactação (abc - letras não coincidentes significam diferença estatística significante $(p \leq 0,05)$ - Teste de Dunnett T3)

gordura no leite. Afora isso, a produção média dos animais por lactação, nas propriedades utilizadas nesta pesquisa, variava entre 5.0000 e 8.000 litros, sendo que, nestas condições, a quantidade de concentrados utilizados não ultrapassaria limites que pudessem interferir na fermentação ruminal e no seu $\mathrm{pH}$ e que poderiam determinar menor produção de gordura no leite. ${ }^{17}$

$\mathrm{Na}$ figura 3 observou-se a significativa influência da fase colostral nos teores lácteos de sólidos totais durante o primeiro mês de lactação. Em amostras colhidas com até 12 horas de lactação $(18,18 \pm 3,20 \mathrm{~g} / \mathrm{dL})$ foram encontrados os valores médios máximos para essa variável, sendo observado em amostras colhidas entre 12 e 24 horas após

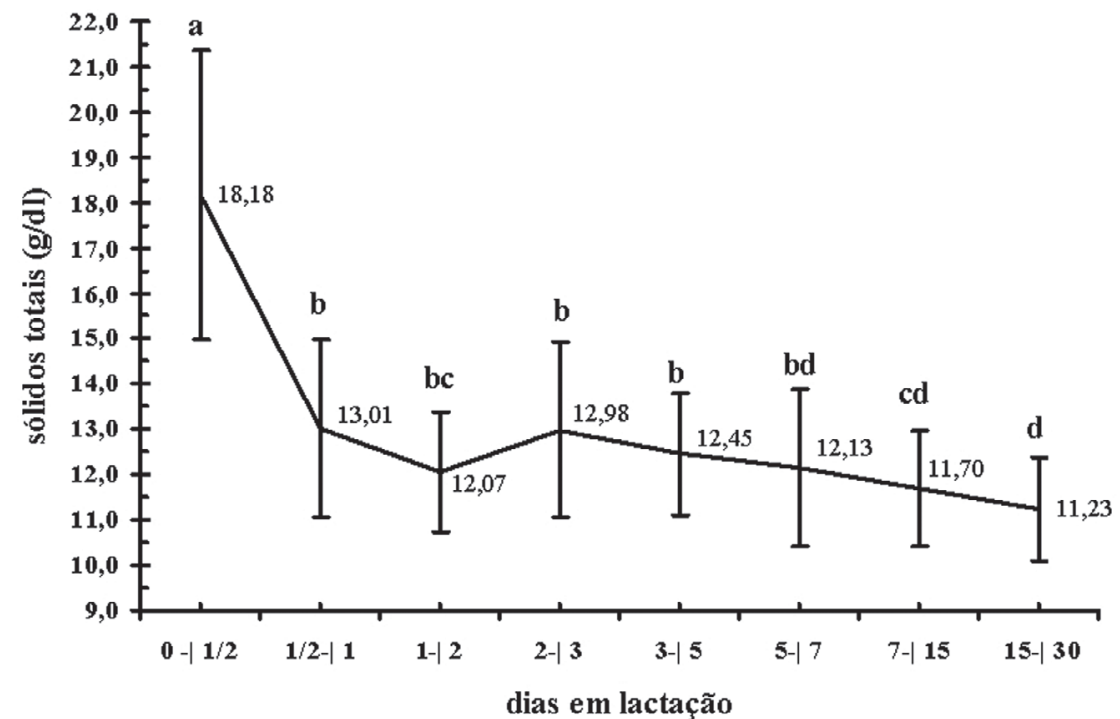

Figura 3 - Valores médios dos teores de sólidos totais na secreção láctea de vacas da raça Jersey no primeiro mês de lactação (abcd - letras não coincidentes significam diferença estatística significante $(p \leq 0,05)$ - Teste de Dunnett T3) 
o parto $(13,01 \pm 1,98 \mathrm{~g} / \mathrm{dL})$ uma abrupta diminuição dos teores lácteos de sólidos totais.Estas observações estão em concordância com Oyeniyi e Hunter ${ }^{15}$ e Parrish et al. ${ }^{16}$. Entre o $2^{\circ}$ dia e o $7^{\circ}$ dia de lactação os valores de sólidos totais oscilaram entre $12,07 \pm 1,33$ e 12,13 $\pm 1,73$ $\mathrm{g} / \mathrm{dL}$ sem que diferenças estatísticas fossem observadas. A seguir, com o evoluir da lactação, observou-se que a diminuição gradual nos seus teores, sendo encontrado no grupo composto por amostras colhidas entre o $15^{\circ}$ e $30^{\circ}$ dia de lactação o valor mínimo para essa variável $(11,23 \pm 1,13 \mathrm{~g} /$ $\mathrm{dL})$. Anteriormente Estrella, ${ }^{3}$ Oyeniyi e Hunter ${ }^{15}$, Ontsouka, Bruckmaier e Blum ${ }^{14} \mathrm{e}$ Parrish et al. ${ }^{16}$ descreveram uma diminuição nos teores de sólidos totais no primeiro mês de lactação.

$\mathrm{Na}$ fase colostral, considerando-se as 68 amostras de colostro sem isolamento bacteriano obtidas nas primeiras 24 horas após o parto $\left(1^{\circ}\right.$ dia de lactação) foram estabelecidos, baseados nos interválos de confiança, os seguintes valores de referência: proteína - entre 7,35 e 11,45 g/dL; gordura - 0,98 e 2,00 g/dL; e sólidos totais - entre 12,39 e 19,45 g/dL (Tabela 2).

$\mathrm{Na}$ fase de transição do colostro para o leite, considerando-se as 231 amostras de secreção láctea sem crescimento bacteriano obtidas entre o $2^{\circ}$ e $7^{\circ}$ dia de lactação devem ser adotados os seguintes valores de referencia: proteína - entre 4,16 e 5,03 g/ $\mathrm{dL}$; gordura - 1,63 e 3,72 g/dL e sólidos totais - entre 11,63 e 13,53 g/dL (Tabela 2).

Embora o objetivo desta pesquisa não fosse a apresentação de valores de referência para o período da lactação plena, não foram encontrados durante a revisão bibliográfica pesquisas na qual os valores de referência para proteína, gordura e sólidos totais do leite de bovinos da raça Jersey tenham sido estabelecidos. Face à isso optouse pela apresentação desses valores de referência, utilizando para tal finalidade os resultados obtidos no grupo composto por amostras de leite obtidas entre o $7^{\circ}$ e $30^{\circ}$ dia de lactação e que variaram, considerando o intervalo de confiança, entre 3,48 e 4,20 g/ dL para proteína; entre 1,70 e $2,82 \mathrm{~g} / \mathrm{dL}$ para gordura e entre 10,94 e 12,02 g/dL para sólidos totais (Tabela 2).

\section{Conclusões}

Os teores de proteína na secreção láctea diminuíram abruptamente do $1^{\circ}$ para

Tabela 2 -Valores de referência (intervalo de confiança*) dos teores de cloretos, lactose e índice cloretos/lactose na secreção láctea de vacas da raça Jersey no primeiro mês de lactação

\begin{tabular}{ccccc}
\hline $\begin{array}{c}\text { Dias em } \\
\text { lactação }\end{array}$ & $\begin{array}{c}\text { Número de } \\
\text { amostras }\end{array}$ & $\begin{array}{c}\text { Proteína } \\
\mathbf{( g / d} \text { (l) }\end{array}$ & $\begin{array}{c}\text { Gordura } \\
\mathbf{( g / d )}\end{array}$ & $\begin{array}{c}\text { Sólidos Totais } \\
\mathbf{( g / d} / \mathbf{d})\end{array}$ \\
\hline $0 \dashv 1 / 2$ & 27 & $10,46-11,45$ & $2,00-3,82$ & $16,92-19,45$ \\
$1 / 2 \dashv 1$ & 41 & $7,35-8,84$ & $0,98-1,72$ & $12,39-13,64$ \\
$1 \dashv 2$ & 47 & $4,64-5,03$ & $1,63-2,51$ & $11,68-12,47$ \\
$2 \dashv 3$ & 50 & $4,33-4,62$ & $2,47-3,72$ & $12,43-13,53$ \\
$3 \dashv 5$ & 86 & $4,16-4,46$ & $2,39-2,97$ & $12,16-12,74$ \\
$5 \dashv 7$ & 48 & $4,00-4,20$ & $2,48-3,21$ & $11,63-12,64$ \\
$7 \dashv 15$ & 62 & $3,84-4,20$ & $2,17-2,82$ & $11,38-12,02$ \\
$15 \dashv 30$ & 57 & $3,48-3,64$ & $1,70-2,22$ & $10,94-11,54$ \\
\hline
\end{tabular}

*- intervalo de confiança, intervalo no qual estão compreendidos $95 \%$ dos valores da população 
o $2^{\circ}$ dia de lactação, enquanto os teores de sólidos totais diminuíram abruptamente nas primeiras 24 horas após o parto.

Após oscilaram muito nos primeiros três dias de lactação, observou-se que os valores de gordura diminuíam atingindo os valores mínimos entre o $15^{\circ}$ e $30^{\circ}$ dia de lactação.

\section{Agradecimentos}

À FAPESP, pelo Auxílio Pesquisa Proc. $n^{\circ}$ 04/12049-5 e Bolsa de Mestrado Proc. no 03/10224-l.

\section{Proteins, fats and total solids content in milk from Jersey cows raised in São Paulo State during the first month of lactation}

\section{Abstract}

With the aim to establish reference values of the protein, fat and total solids of milk from Jersey cows, raised in the State of São Paulo, during the first month of lactation, as well as to evaluate the influence of the colostral phase, 418 milk samples, obtained from healthy mammary glands without bacterial growth, were analized. Milk samples were aseptically collected before milking and protein, fat and total solids determined by infrared radiation. The milk protein level decrease from first to second day of lactation, while milk total solids level decreased during the first 24 hours after parturition. Milk fat level oscillated in the first 3 days of lactation and then decreased to the minimum values between 15-30 days of lactation. We suggest, for the first 24 hours of lactation (colostral phase) the use of the following reference values: protein- between 7,35 and $11,45 \mathrm{~g} / \mathrm{dl}$; fat- between 0,98 and $2,00 \mathrm{~g} / \mathrm{dl}$; total solids - between 12,39 and 19,45 g/dl
Key words:

Milk.

Proteins.

Fat.

Total solids.

Cattle Jersey breed.

Colostral phase.

\section{Referências}

$1 \mathrm{SANT}^{\prime}$ ANA, V. A. C. Proteinograma do leite de vacas: padrões e variabilidade. 2004. 161 f. Dissertação (Mestrado em Clínica Veterinária) - Faculdade de Medicina Veterinária e Zootecnia, Universidade de São Paulo, São Paulo, 2004.

2 BIRGEL JUNIOR, E. H. Características físicoquímicas, celulares e microbiológicas do leite de bovinos das raças Holandesa, Gir e Girolando criados no Estado de São Paulo. 2006. 335 f. Tese (Livre Docência) - Faculdade de Medicina Veterinária e Zootecnia, Universidade de São Paulo, São Paulo, 2006.

3 ESTRELLA, S. L. G. Características físico-químicas e celulares do leite de bovinos da raça holandesa, criados no estado de São Paulo. Influência da fase da lactação, dos quartos mamários, do número de lactações e do isolamento bacteriano. 2001. 162 f. Dissertação (Mestrado em Clínica Veterinária) - Faculdade de Medicina Veterinária e Zootecnia, Universidade de São Paulo, São Paulo, 2001.

4 MARQUES, R. S. Avaliação das características físicoquímicas e celulares do leite de bovinos da raça girolando, criados no estado de São Paulo. 2003. 167 f. Dissertação (Mestrado em Clínica Veterinária) Faculdade de Medicina Veterinária e Zootecnia,
Universidade de São Paulo, São Paulo, 2003

5 ROSENFELD, A. M. F. Retenção láctea: fator etiológico predisponente às inflamações da glândula mamária de bovinos. Características físico-químicas, celulares e microbiológicas do leite. 2005. 128 f. Dissertação (Mestrado em Clínica Veterinária) Faculdade de Medicina Veterinária e Zootecnia, Universidade de São Paulo, São Paulo, 2005.

6 BIRGEL, E. H. Semiologiada glândula mamária de ruminantes. In: FEITOSA, F. L. (Ed.). Semiologia veterinária: a arte do diagnóstico. São Paulo: Roca, 2004. p. 353-399.

7 LENNETTE, E. H. (Ed.). Manual of clinical microbiology. $9^{\text {th }}$ ed. Washington, D. C.: American Society for Microbiology, 2007. 2488 p.

8 SAMPAIO, I. B. M. Estatística aplicada à experimentação animal. Belo Horizonte: Fundação de Ensino e Pesquisa em Medicina Veterinária e Zootecnia, 1998. 221 p.

9 SCHEFFÉ, H. The analysis of variance. New York: John Wiley, 1959. 477 p.

10 ANDREW, S. M. Effect of composition of colostrum and transition milk from Holstein heifers on specificity rates of antibiotic residue tests. American Dairy Science Association, v. 84, n. 1, p. 100-106, 2001. 
11 MAUNSELL, F.; MORIN, D.; CONSTABLE, P.; HURLEY, W., MCCOY, G. C.; KAKOMA, I.; ISAACSON, R. E. Effects of mastitis on the volume and composition of colostrums produced by Holstein cows. Journal of Dairy Science, v. 81, n. 5, p. 1291-1299, 1998.

12 NG-KWAI-HANG, K. F.; HAYES, J. F.; MOXLEY, J. E.; MONARDES, H. G. Percentages of protein and nonprotein nitrogen with varying fat and somatic cells in bovine milk. Journal of Dairy Science, v. 68, n. 5, p. 1993-1998, 1982.

13 NG-KWAI-HANG, K. F.; HAYES, J. F.; MOXLEY, J. E.; MONARDES, H. G. Environmental Influences on protein content and composition of bovine milk. Journa of Dairy Science, v. 65, n. 10, p. 1257-1262, 1982.

14 ONTSOUKA, C. E.; BRUCKMAIER, R. M.; BLUM, J. W. Fractionized milk composition during removal of colostrum and mature milk. Journal of Dairy Science v. 86, n. 6, p. 2005-2011, 2003.

15 OYENIYI, O. O.; HUNTER A. G. Colostral constituents including immunoglobulins in the first three milkings postpartum. Journal of Dairy Science, v. 61, p. $44-48,1978$

16 PARRISH, D. B.; WISE, G. H.; HUGHES, J. S.; ATKESON, F. W. Properties of the colostrum of dairy cow Vyield, specific gravity and concentrations of total solids and its various components of colostrum and early milk. Journal of Dairy Science, v. 33, n. 6, p. 457465, 1950.

17 CARVALHO, M. P. Manipulação da composição do leite por meio do balanceamento de dietas de vacas leiteiras. In: FONSECA, L. F. L.; SANTOS, M. V. Qualidade do leite e controle de mastite. São Paulo: Lemos Editorial, 2000. 175 p.

18 BRITO, J. R. F.; CALDEIRA, G. A. V.; VERNEQUE, R. S.; BRITO, M. A. V. P. Sensibilidade e especificidade do "California Mastitis Test"como recurso diagnóstico da mastite em relação à contagem de células somáticas. Pesquisa Veterinária Brasileira, v. 17, n. 2, p. 49-53, 1997. 